\title{
Prognostic impact of fibroblast growth factor receptor 2 gene amplification in patients receiving fluoropyrimidine and platinum chemotherapy for metastatic and locally advanced unresectable gastric cancers
}

\author{
Seyoung Seo ${ }^{1, *}$, Seong Joon Park ${ }^{1, *}$, Min-Hee Ryu ${ }^{1, *}$, Sook Ryun Park ${ }^{1}$, Baek-Yeol \\ Ryoo ${ }^{1}$, Young Soo Park ${ }^{2}$, Young-Soon $\mathrm{Na}^{3}$, Chae-Won Lee ${ }^{3}$, Ju-Kyung Lee ${ }^{3}$ and \\ Yoon-Koo Kang ${ }^{1}$ \\ ${ }^{1}$ Department of Oncology, Asan Medical Center, University of Ulsan College of Medicine, Seoul, Korea \\ 2 Department of Pathology, Asan Medical Center, University of Ulsan College of Medicine, Seoul, Korea \\ ${ }^{3}$ Asan Institute for Life Science, Asan Medical Center, University of Ulsan College of Medicine, Seoul, Korea \\ * Seyoung Seo, Seong Joon Park, Min-Hee Ryu have contributed equally to this study as first authors \\ Correspondence to: Yoon-Koo Kang, email: ykkang@amc.seoul.kr \\ Keywords: FGFR2; amplification; advanced gastric cancer; prognosis; quantitative real-time polymerase chain reaction \\ Received: July 20, 2016 \\ Accepted: October 22, 2016 \\ Published: October 27, 2016 \\ Copyright: Seo et al. This is an open-access article distributed under the terms of the Creative Commons Attribution License (CC-BY), which \\ permits unrestricted use, distribution, and reproduction in any medium, provided the original author and source are credited.
}

\section{ABSTRACT}

Although Fibroblast growth factor receptor (FGFR) 2 gene amplification and its prognostic significance have been reported in resectable gastric cancers, information on these features remains limited in the metastatic setting. The presence of FGFR2 amplification was assessed in formalin-fixed, paraffin-embedded tissues using a quantitative PCR-based gene copy number assay with advanced gastric cancer cohorts. A total of $\mathbf{3 2 7}$ patients with tumor portion of $\geq 70 \%$ were analyzed for clinical features. Among these patients, 260 who received first-line fluoropyrimidine and platinum chemotherapy were analyzed for survival.

Sixteen of 327 patients (4.9\%) exhibited FGFR2 amplification. The amplification group showed associations with age $<65$ years, Borrmann type 4 disease, poor performance status, poorly differentiated histology, extra-abdominal lymph node metastases, and bone metastases. The median overall survival (OS) and progressionfree survival (PFS) were found to be $\mathbf{1 2 . 7}$ and $\mathbf{5 . 8}$ months, respectively. In univariate analysis, PFS did not differ between amplification and no amplification groups (hazard ratio $[H R]=1.34,95 \%$ confidence interval $[C I]: 0.78-2.31, p=0.290$ ), although the OS was significantly shorter in the amplification group (HR=1.92, 95\% CI: 1.13-3.26, $p=0.015)$. However, multivariate analysis indicated that FGFR2 amplification was not an independent prognostic factor for OS ( $H R=1.42,95 \% \mathrm{CI}: 0.77-2.61, p=0.261$ ).

Although FGFR2 amplification is associated with poorer OS, it does not appear to be an independent prognostic predictor in patients with advanced gastric cancer treated with palliative fluoropyrimidine and platinum chemotherapy.

\section{INTRODUCTION}

Although the prognosis of advanced gastric cancer has improved after introduction of cytotoxic chemotherapy [1], gastric cancer remains one of the leading causes of cancer-related death worldwide $[2,3]$. Various chemotherapeutic agents have been investigated for the management of metastatic gastric cancer, including infusional 5-fluorouracil, CDDP, anthracyclines, taxanes, oral fluoropyrimidines, and oxaliplatin [4-8]. At present, a standard chemotherapy protocol for gastric cancer has not been established; however, the combination of CDDP and infusional 5-fluorouracil, with or without epirubicin, is most commonly prescribed, and is considered as a 
reference treatment by most regulatory agencies when evaluating newer treatments. Furthermore, several phase III trials have demonstrated that oral fluoropyrimidines (such as S-1 and capecitabine) can replace infusional 5-fluorouracil in the treatment of gastric cancer [6-9].

Given the disappointing clinical outcomes of malignant gastric cancer, targeted treatments are being actively investigated. The combination of trastuzumab with chemotherapy in HER2-positive advanced gastric cancer patients as first-line therapy and the addition of ramucirumab to taxane in non-selective advanced gastric cancer patients as second-line therapy exhibited modest survival benefits $[10,11]$, whereas other targeted agents, including bevacizumab, everolimus, and cetuximab, did not show overall survival gain without the use of biomarker enrichment strategies [12-14]. Despite these efforts to improve survival in gastric cancer, most patients with advanced gastric cancer usually have a median overall survival (OS) of $<12$ months. Thus, a considerable amount of research is required to discover novel treatment targets for patients with advanced gastric cancer.

The regulation of the fibroblast growth factor (FGF) signaling pathway is important for normal growth control, and the genetic alteration of the FGF receptor (FGFR) reportedly enhances downstream signaling and is related to tumorigenesis $[15,16]$. In particular, an increase in the FGFR2 copy number was reported in cases of breast cancer $[17,18]$ and poorly differentiated gastric cancer $[19,20]$. Furthermore, a few studies examined the clinicopathologic features of FGFR2-amplified gastric cancer and showed that FGFR2 amplification was associated with poorer prognosis [21-23]. Accordingly, FGFR2 amplification was considered as a reasonable treatment target and predictive biomarker for small molecule tyrosine kinase inhibitors or antibodies to FGFR2, including dovitinib, BGJ398, Ki23057, AZD4547, and GP369 [24-28]. However, previous studies on gastric cancer were conducted in patients with localized resectable gastric cancer. Hence, these findings cannot be directly applied to patients with recurrent or unresectable gastric cancer who are indicated for palliative chemotherapy.

Fluorescence in situ hybridization (FISH) is considered as the standard method for detecting gene amplification. However, due to the high cost and long procedure duration of FISH testing, real-time quantitative polymerase chain reaction (qPCR)-based gene copy number assay was suggested as a possible alternative to detect $F G F R 2$ amplification [21, 29]. In our previous study, we showed that the FGFR2/CEP10 ratio, determined via FISH, were very well correlated with the results of the qPCR-based gene copy number assay, with a cut-off value of 8 for FGFR2 amplification [29].

In the present study, we aimed to investigate the association of FGFR2 amplification with the clinicopathologic features and prognostic significance in patients with unresectable gastric cancer treated with fluoropyrimidine and platinum (FP) as first-line chemotherapy. Moreover, we assessed the FGFR2 amplification status by using qPCR, a sensitive but less expensive method.

\section{RESULTS}

\section{Patient characteristics}

The formalin-fixed paraffin-embedded (FFPE) samples of a total of 327 patients had a tumor portion of $>70 \%$, and were adequate for analyzing the relationship between FGFR2 amplification and clinicopathologic factors. The patients had a median age of 58 years (range, 23-85 years); moreover, $68.8 \%$ of patients had initially metastatic disease, whereas the remaining presented with recurring and locally advanced unresectable disease. At the time of diagnosis, 288 (88.1\%) patients had an Eastern Cooperative Oncology Group (ECOG) performance status of $0-1$ (Table 1). The median copy numbers on FGFR2

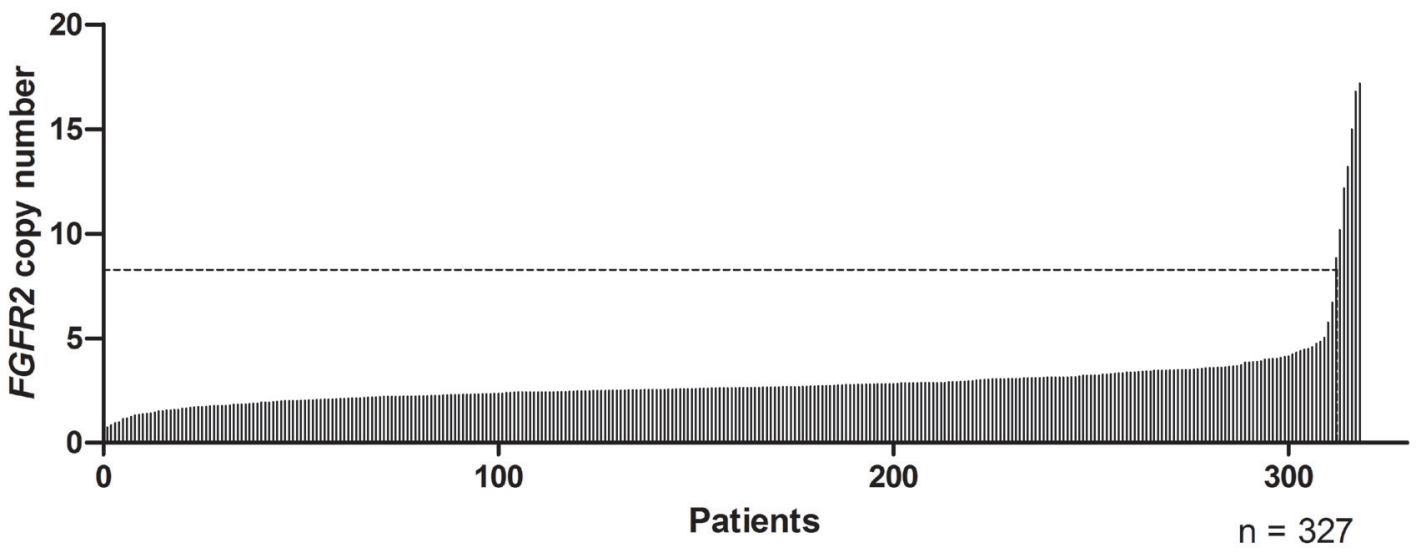

Figure 1: FGFR2 copy numbers determined with a quantitative PCR-based assay in metastatic or locally advanced gastric cancer. FGFR 2 copy number of $\geq 8$ was observed in 16 cases and 9 data points are outside the axis limits on this graph. 
Table 1: Baseline characteristics of the study patients $(n=327)$

\begin{tabular}{|c|c|c|c|c|}
\hline & & $n$ & $(\%)$ & Median (range) \\
\hline$F G F R 2$ qPCR value & gene copy number $\geq 8$ & 16 & 4.9 & $2.64(0.73-504.04)$ \\
\hline Gender & Male & 226 & 69.1 & \\
\hline Age & $\geq 65$ years & 93 & 35.9 & $58(23-85)$ \\
\hline ECOG PS & 0 or 1 & 228 & 88.1 & \\
\hline \multirow{5}{*}{ Borrmann type } & I & 17 & 5.2 & \\
\hline & II & 71 & 21.7 & \\
\hline & III & 178 & 54.4 & \\
\hline & IV & 50 & 15.3 & \\
\hline & Not available & 11 & 3.4 & \\
\hline \multirow{3}{*}{ Histology } & WD/MD & 117 & 35.8 & \\
\hline & $\mathrm{PD} / \mathrm{SRC} /$ mucinous & 204 & 62.4 & \\
\hline & Others & 6 & 1.8 & \\
\hline \multirow{3}{*}{ HER2/neu ${ }^{a}$} & Positive & 19 & 5.8 & \\
\hline & Negative & 103 & 31.5 & \\
\hline & Not tested & 205 & 62.8 & \\
\hline No gastrectomy & & 211 & 64.5 & \\
\hline \multirow{3}{*}{ Disease status } & Initially metastatic & 215 & 68.8 & \\
\hline & Recurred & 99 & 30.3 & \\
\hline & Locally advanced & 13 & 0.9 & \\
\hline \multirow{6}{*}{ Metastatic organ } & Peritoneum & 157 & 48.0 & \\
\hline & Liver & 95 & 29.1 & \\
\hline & Lung & 20 & 6.1 & \\
\hline & Intraabdominal distant LN & 154 & 47.1 & \\
\hline & Extra-abdominal distant LN & 31 & 9.5 & \\
\hline & Bone & 27 & 8.3 & \\
\hline Hemoglobin $^{\mathrm{b}, \mathrm{c}}$ & $\leq$ lower normal limit & 223 & 68.3 & $11.7(6.7-17.4)$ \\
\hline White blood cell ${ }^{\mathrm{c}}$ & $\geq 10000 / \mathrm{mm}^{3}$ & 47 & 14.4 & $6850(2200-48700)$ \\
\hline Platelet $^{\mathrm{c}}$ & $\leq 150 \times 10^{3} / \mathrm{mm}^{3}$ & 38 & 11.9 & $264(14-646) \times 10^{3}$ \\
\hline Albumin $^{\mathrm{d}}$ & $<3.3 \mathrm{~g} / \mathrm{dL}$ & 104 & 31.8 & $3.6(1.7-5.3)$ \\
\hline Alkaline phosphatase ${ }^{c}$ & $>120 \mathrm{IU} / \mathrm{L}$ & 71 & 21.7 & $79.5(29-1294)$ \\
\hline Total bilirubin $^{\mathrm{c}}$ & $>1.2 \mathrm{mg} / \mathrm{dL}$ & 29 & 8.9 & $0.6(0.2-6)$ \\
\hline \multirow{3}{*}{ Risk groups ${ }^{c, e}$} & Good $(0-1)$ & 154 & 47.1 & \\
\hline & Moderate (2-3) & 112 & 34.3 & \\
\hline & Poor $(\geq 4)$ & 52 & 15.9 & \\
\hline
\end{tabular}

Abbreviations: $q P C R$, quantitative polymerase chain reaction; ECOG PS, Eastern Cooperative Oncology Group Performance Status; $W D$, well differentiated; $M D$, moderately differentiated; $P D$, poorly differentiated; $S R C$, signet ring cell carcinoma; $L N$, lymph node

${ }^{a}$ HER2/neu-positive was defined as a positive score of $\geq 2$ on immunohistochemistry and/or positive results from silver in situ hybridization

${ }^{\mathrm{b}}$ Hemoglobin $\leq 12 \mathrm{~g} / \mathrm{dL}$ for women and $\leq 13 \mathrm{~g} / \mathrm{dL}$ for men.

'Initial complete blood count, alkaline phosphatase level, bilirubin level, and scores of the Asan Medical Center prognostic model were not available for 9 patients $(2.8 \%)$.

${ }^{\mathrm{d}}$ Albumin levels were not available in 11 patients $(3.4 \%)$

${ }^{\mathrm{e}}$ According to the Asan Medical Center prognostic model 
Table 2: Relationship between $c$ amplification and the clinicopathologic features $(n=327)$

\begin{tabular}{|c|c|c|c|c|}
\hline & & $F G F R 2 \mathrm{gCN}$ of $<8$ & $F G F R 2 \mathrm{gCN}$ of $\geq 8$ & $p$ \\
\hline & & $(n=311,95.1 \%)$ & $(n=16,4.9 \%)$ & \\
\hline \multirow{3}{*}{ Age } & Median (range) & $58(23-85)$ & $50.5(32-66)$ & \\
\hline & $<65$ years & $219(70.4)$ & $15(93.8)$ & 0.047 \\
\hline & $\geq 65$ years & $92(29.6)$ & $1(6.3)$ & \\
\hline \multirow{2}{*}{ Gender } & Male & $216(69.5)$ & $10(62.5)$ & 0.584 \\
\hline & Female & $95(30.5)$ & $6(37.5)$ & \\
\hline \multirow{2}{*}{ ECOG PS } & $0-1$ & $277(89.1)$ & $11(68.8)$ & 0.031 \\
\hline & $2-4$ & $34(10.9)$ & $5(31.3)$ & \\
\hline \multirow{2}{*}{ Bormann type } & $\mathrm{I} / \mathrm{II} / \mathrm{III}$ & $257(85.7)$ & $9(56.3)$ & 0.006 \\
\hline & IV & $43(14.3)$ & $7(43.8)$ & \\
\hline \multirow{2}{*}{ Histology } & WD/MD & $115(37.7)$ & $2(12.5)$ & 0.041 \\
\hline & PD/SRC/mucinous & $190(62.3)$ & $14(87.5)$ & \\
\hline \multirow{2}{*}{ Peritoneal metastasis } & No & $164(52.7)$ & $6(37.5)$ & 0.234 \\
\hline & Yes & $147(47.3)$ & $10(62.5)$ & \\
\hline \multirow{2}{*}{ Liver metastasis } & No & $218(70.1)$ & $14(87.5)$ & 0.166 \\
\hline & Yes & $93(29.9)$ & $2(12.5)$ & \\
\hline \multirow{2}{*}{ Lung metastasis } & No & $292(93.9)$ & $15(93.8)$ & 1.0 \\
\hline & Yes & $19(6.1)$ & $1(6.3)$ & \\
\hline \multirow{2}{*}{$\begin{array}{l}\text { Intraabdominal distant LN } \\
\text { metastasis }\end{array}$} & No & $163(52.4)$ & $10(62.5)$ & 0.43 \\
\hline & Yes & $148(47.6)$ & $6(37.5)$ & \\
\hline \multirow{2}{*}{$\begin{array}{l}\text { Extra-abdominal distant LN } \\
\text { metastasis }\end{array}$} & No & $285(91.6)$ & $11(68.8)$ & 0.011 \\
\hline & Yes & $26(8.4)$ & $5(31.3)$ & \\
\hline \multirow{2}{*}{ Bone metastasis } & No & $289(92.9)$ & $11(68.8)$ & 0.006 \\
\hline & Yes & $22(7.1)$ & $5(31.3)$ & \\
\hline \multirow{2}{*}{ Hemoglobin ${ }^{\mathrm{a}, \mathrm{b}}$} & $>\mathrm{LNL}$ & $89(29.5)$ & $6(37.5)$ & 0.576 \\
\hline & $\leq \mathrm{LNL}$ & $213(70.5)$ & $10(62.5)$ & \\
\hline \multirow{2}{*}{ White blood cell ${ }^{\mathrm{b}}$} & $<10000 / \mathrm{mm}^{3}$ & $257(85.1)$ & $14(87.5)$ & 1.0 \\
\hline & $\geq 10000 / \mathrm{mm}^{3}$ & $45(14.9)$ & $2(12.5)$ & \\
\hline \multirow{2}{*}{ Platelet $^{b}$} & $>150 \times 10^{3} / \mathrm{mm}^{3}$ & $268(88.7)$ & $12(75.0)$ & 0.11 \\
\hline & $\leq 150 \times 10^{3} / \mathrm{mm}^{3}$ & $34(11.3)$ & $4(25.0)$ & \\
\hline \multirow{2}{*}{ Albumin $^{c}$} & $>3.3 \mathrm{~g} / \mathrm{dL}$ & $202(67.1)$ & $10(66.7)$ & 1.0 \\
\hline & $\leq 3.3 \mathrm{~g} / \mathrm{dL}$ & $99(32.9)$ & $5(33.3)$ & \\
\hline \multirow{2}{*}{ Alkaline phosphatase ${ }^{b}$} & $\leq 120 \mathrm{IU} / \mathrm{L}$ & $235(77.8)$ & $12(75.0)$ & 1.0 \\
\hline & $>120 \mathrm{IU} / \mathrm{L}$ & $67(22.2)$ & $4(25.0)$ & \\
\hline \multirow{2}{*}{ Total bilirubin $^{\mathrm{b}}$} & $\leq 1.2 \mathrm{mg} / \mathrm{dL}$ & $274(90.7)$ & $15(93.8)$ & 1.0 \\
\hline & $>1.2 \mathrm{mg} / \mathrm{dL}$ & $28(9.3)$ & $1(6.3)$ & \\
\hline \multirow{3}{*}{ Risk groups $^{\mathrm{b}, \mathrm{d}}$} & Good & $147(48.7)$ & $7(43.8)$ & 0.004 \\
\hline & Moderate & $110(36.4)$ & $2(12.5)$ & \\
\hline & Poor & $45(14.9)$ & $7(43.8)$ & \\
\hline
\end{tabular}

Abbreviations: $g C N$, gene copy numbers; $E C O G$ PS, Eastern Cooperative Oncology Group Performance Status; WD, well differentiated; $M D$, moderately differentiated; $P D$, poorly differentiated; $S R C$, signet ring cell carcinoma; $L N$, lymph node; $L N L$, lower normal limit

${ }^{a}$ Hemoglobin $\leq 12 \mathrm{~g} / \mathrm{dL}$ for women and $\leq 13 \mathrm{~g} / \mathrm{dL}$ for men.

${ }^{b}$ Initial complete blood count, alkaline phosphatase level, bilirubin level, and scores of the Asan Medical Center prognostic model were not available for 9 patients $(2.8 \%)$.

${ }^{\mathrm{c}}$ Albumin levels were not available in 11 patients $(3.4 \%)$

${ }^{\mathrm{d} A c c o r d i n g}$ to the Asan Medical Center prognostic model 
qPCR was 2.64 (range, 0.73-504.04) and the frequency of FGFR2 amplification was $4.9 \%(n=16)$ (Figure 1).

\section{Association between $F G F R 2$ amplification and the clinicopathologic features}

The clinical characteristics were compared between the patients with and without FGFR2 amplification. The amplification group showed an association with age $<65$ years $(93.6 \% v s .70 .4 \%, p=0.047)$, ECOG performance status $\geq 2(31.3 \%$ vs. $10.9, p=0.031)$, Borrmann type 4 disease $(43.7 \%$ vs. $13.7 \%, p=0.013)$, poorly differentiated pathology including signet ring cell and mucinous carcinoma $(87.5 \%$ vs. $62.3 \%, p=0.041)$, extraabdominal lymph node metastases $(31.3 \%$ vs. $6.4 \%, p=$ $0.011)$, and bone metastases $(31.3 \%$ vs $7.1 \%, p=0.006)$. After stratifying the patients according to risk by using our previously described prognostic model for metastatic or recurrent gastric cancer [30], we found that the amplification group was more closely related to the poor prognostic group (43.8\% vs. $14.9 \%, p=0.004)$ (Table 2$)$.

\section{Association between FGFR2 amplification and survival outcome}

A total of 260 patients treated with the FP regimen were included in the survival analysis; among these patients, 172 presented with measurable lesions. An objective response was observed in 81 of 172 patients (47.7\%), and the overall response rate did not significantly differ between the amplification and no amplification groups $(55.6 \%$ vs. $43.9 \%, p=1.000)$. Overall, $88.8 \%$ of the patients had died at the time of analysis. Over a median follow-up of 28.2 months (range, 8.2-68.5 months), the median OS and progression free survival (PFS) durations were 12.7 months $(95 \%$ confidence interval [CI]: 11.0$14.5)$ and 5.8 months (95\% CI: 4.8-6.8), respectively.

Univariate analysis did not indicate PFS difference between the amplification and no amplification groups (hazard ratio $[\mathrm{HR}]=1.34,95 \% \mathrm{CI}: 0.78-2.31, p=$ 0.290 ), although the OS duration was significantly shorter in the amplification group ( $\mathrm{HR}=1.92,95 \% \mathrm{CI}$ : 1.13-3.26, $p=0.015$ ) (Figure 2). Patients who did not undergo gastrectomy and those with Borrmann type 4

A

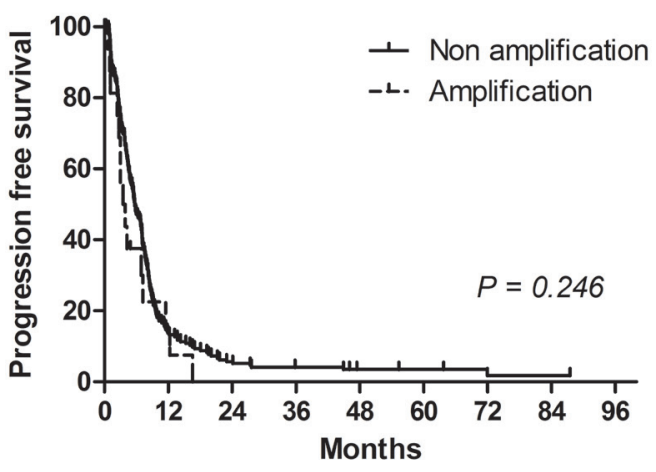

B

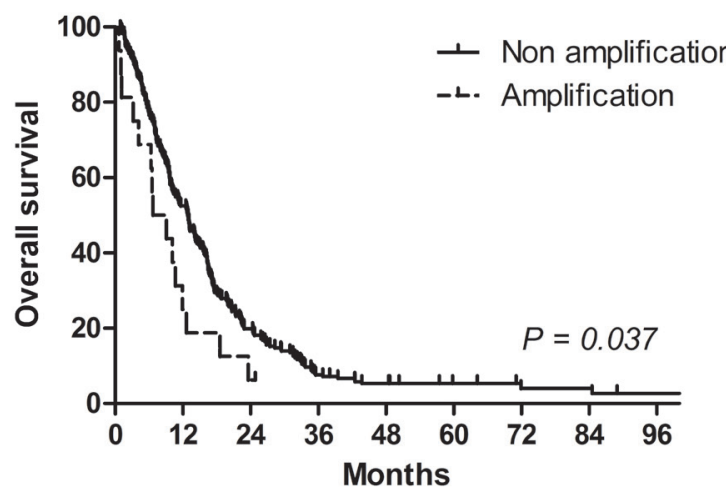

Figure 2: Progression-free survival and overall survival according to FGFR2 amplification. A. progression free survival was not significantly different between $F G F R 2$ amplification group and no amplification group. B. $F G F R 2$ amplification was associated with shorter overall survival. 
Table 3: Univariate analysis of progression-free and overall survival $(n=260)$

\begin{tabular}{|c|c|c|c|c|c|c|c|}
\hline & & \multicolumn{3}{|c|}{ Progression-free survival } & \multicolumn{3}{|c|}{ Overall survival } \\
\hline & & HR & $95 \% \mathrm{CI}$ & $p$ & HR & $95 \% \mathrm{CI}$ & $p$ \\
\hline Gender & Female & 1.02 & $0.76-1.37$ & 0.907 & 0.99 & $0.74-1.33$ & 0.952 \\
\hline Age & $\geq 65$ years & 0.88 & $0.65-1.21$ & 0.434 & 1.17 & $0.89-1.56$ & 0.267 \\
\hline ECOG PS & $2-3$ & 1.52 & $1.00-2.32$ & 0.052 & 2.64 & $1.82-3.82$ & $<0.001$ \\
\hline Bormann type & IV & 1.95 & $1.36-2.81$ & $<0.001$ & 1.76 & $1.25-2.48$ & 0.001 \\
\hline \multicolumn{2}{|c|}{$\mathrm{PD} / \mathrm{SRC} /$ mucinous histology } & 1.25 & $0.93-1.69$ & 0.139 & 1.12 & $0.85-1.48$ & 0.411 \\
\hline \multicolumn{2}{|l|}{ No gastrectomy } & 1.64 & $1.21-2.21$ & 0.001 & 1.99 & $1.47-2.69$ & $<0.001$ \\
\hline \multicolumn{2}{|c|}{ Peritoneal metastasis } & 0.98 & $0.74-1.28$ & 0.853 & 1.17 & $0.90-1.53$ & 0.233 \\
\hline \multicolumn{2}{|l|}{ Liver metastasis } & 1.12 & $0.83-1.51$ & 0.475 & 1.09 & $0.82-1.45$ & 0.551 \\
\hline \multicolumn{2}{|l|}{ Lung metastasis } & 1.85 & $1.00-3.40$ & 0.048 & 1.83 & $1.02-3.28$ & 0.042 \\
\hline \multicolumn{2}{|c|}{ Intraabdominal distant LN } & 0.99 & $0.76-1.30$ & 0.938 & 0.89 & $0.69-1.16$ & 0.382 \\
\hline \multicolumn{2}{|c|}{ Extra-abdominal distant LN } & 1.03 & $0.65-1.66$ & 0.891 & 1.32 & $0.84-2.07$ & 0.227 \\
\hline \multicolumn{2}{|l|}{ Bone metastasis } & 2.46 & $1.55-3.90$ & $<0.001$ & 3.53 & $2.28-5.47$ & $<0.001$ \\
\hline Hemoglobin $^{\mathrm{a}}$ & $\leq \mathrm{LNL}$ & 0.79 & $0.59-1.06$ & 0.116 & 0.99 & $0.75-1.31$ & 0.934 \\
\hline WBC & $\geq 10000 / \mathrm{mm}^{3}$ & 1.01 & $0.67-1.51$ & 0.971 & 1.07 & $0.72-1.59$ & 0.747 \\
\hline Platelet & $\leq 150 \times 10^{3} / \mathrm{mm}^{3}$ & 0.98 & $0.64-1.49$ & 0.906 & 1.15 & $0.77-1.73$ & 0.499 \\
\hline Albumin & $\leq 3.3 \mathrm{~g} / \mathrm{dL}$ & 1.53 & $1.15-2.03$ & 0.003 & 2.22 & $1.69-2.91$ & $<0.001$ \\
\hline ALP & $>120 \mathrm{IU} / \mathrm{L}$ & 1.64 & $1.18-2.28$ & 0.003 & 1.88 & $1.38-2.55$ & $<0.001$ \\
\hline Total bilirubin & $>1.2 \mathrm{mg} / \mathrm{dL}$ & 1.29 & $0.82-2.03$ & 0.267 & 1.31 & $0.86-1.98$ & 0.206 \\
\hline \multirow{3}{*}{ Risk groups ${ }^{\mathrm{b}}$} & Good & 1 & & & 1 & & \\
\hline & Moderate & 1.12 & $0.83-1.50$ & 0.476 & 1.33 & $0.99-1.78$ & 0.055 \\
\hline & Poor & 1.94 & $1.31-2.87$ & 0.001 & 3.19 & $2.22-4.58$ & $<0.001$ \\
\hline$F G F R 2$ qPCR & $\mathrm{gCN} \geq 8$ & 1.34 & $0.78-2.31$ & 0.290 & 1.92 & $1.13-3.26$ & 0.015 \\
\hline
\end{tabular}

Abbreviations: $H R$, hazard ratio; $C I$, confidence interval; ECOG PS, Eastern Cooperative Oncology Group Performance Status; $P D$, poorly differentiated; $S R C$, signet ring cell carcinoma; $L N$, lymph node; $L N L$, lower normal limit; $W B C$, white blood cells; $A L P$, alkaline phosphatase; $q P C R$, quantitative polymerase chain reaction; $g C N$, gene copy number

${ }^{\mathrm{a}}$ Hemoglobin $\leq 12 \mathrm{~g} / \mathrm{dL}$ for women and $\leq 13 \mathrm{~g} / \mathrm{dL}$ for men.

${ }^{\mathrm{b}}$ According to the Asan Medical Center prognostic model

disease, bone metastasis, low albumin levels, or elevated alkaline phosphatase (ALP) levels exhibited poorer PFS. The following factors were significantly associated with a shorter OS: ECOG performance status $\geq 2$, no gastrectomy, Borrmann type 4 disease, bone metastasis, lung metastasis, elevated ALP levels, and low albumin levels (Table 3). However, when the other significant prognostic factors were included, multivariate analysis showed that FGFR2 amplification was not an independent prognostic factor of $\mathrm{OS}(\mathrm{HR}=1.42,95 \% \mathrm{CI}$ : 0.77-2.61, $p=0.261)$. In fact, multivariate analysis indicated that Bormann type IV disease, lung metastasis, and elevated ALP levels were not associated with poor OS, although no gastrectomy, poor ECOG performance status, bone metastasis, and low albumin levels remained significant prognostic factors (Table 4). In addition, when the patients were stratified by risk based on the recommendations of our previous report [30], FGFR2 amplification was not found to be significantly associated with $\mathrm{OS}(\mathrm{HR}=1.61$, 95\% CI: $0.94-2.77, p=0.083)$ or PFS $(\mathrm{HR}=1.26,95 \%$ CI: $0.72-2.19, p=0.418$ ), although risk stratification did show a prognostic significance for OS (moderate risk group: $\mathrm{HR}=1.35,95 \% \mathrm{CI}, 1.01-1.81, p=0.042$; poor risk group: $\mathrm{HR}=3.07,95 \% \mathrm{CI}, 2.12-4.43, p<0.001)$ (Table 4).

\section{DISCUSSION}

We determined the presence of FGFR2 amplification by using the qPCR-based gene copy number assay, and 
Table 4: Multivariate Cox proportional hazard models to confirm the prognostic significance of FGFR2 amplification with other clinical factors $(n=260)$

\begin{tabular}{|l|l|l|l|l|}
\hline & & Hazard ratio & $\begin{array}{l}\text { 95\% } \\
\text { interval }\end{array}$ & confidence \\
\hline No gastrectomy & & 1.47 & $1.05-2.39$ & 0.025 \\
\hline Albumin $<3.3 \mathrm{~g} / \mathrm{dL}$ & & 1.62 & $1.20-2.19$ & 0.002 \\
\hline ECOG PS $\geq 2$ & & 1.68 & $1.13-2.50$ & 0.011 \\
\hline Borrmann type IV & & 1.40 & $0.98-1.99$ & 0.062 \\
\hline Bone metastasis & & 2.49 & $1.58-3.91$ & $<0.001$ \\
\hline Lung metastasis & & 1.87 & $0.98-3.57$ & 0.059 \\
\hline FGFR2 qPCR gCN $\geq 8$ & & 1.61 & $0.94-2.77$ & 0.083 \\
\hline \multirow{2}{*}{ Risk groups ${ }^{\mathrm{a}}$} & Good & 1 & & $1.01-1.81$ \\
\cline { 2 - 5 } & Moderate & 1.35 & $2.13-4.43$ & 0.042 \\
\cline { 2 - 5 } & Poor & 3.07 & $<0.001$ \\
\hline
\end{tabular}

Abbreviations: ECOG PS, Eastern Cooperative Oncology Group Performance Status; $q P C R$, quantitative polymerase chain reaction; $g C N$, gene copy numbers

according to the Asan Medical Center prognostic model

found that FGFR2 amplification was present in $4.9 \%$ of the patients with metastatic or locally advanced unresectable gastric cancer. FGFR2 amplification was also associated with proven poor prognostic factors of gastric cancer, including poor performance status and bone metastases. Although FGFR2 amplification was significantly associated with a shorter OS, it was not found to be an independent poor prognostic factor in patients with metastatic and locally advanced unresectable gastric cancer, and could not predict the chemotherapy response. To our knowledge, our present study is the largest retrospective analysis to date of the clinical and prognostic implications of FGFR2 amplification in metastatic or locally advanced unresectable gastric cancer. Notably, the prognostic impact of FGFR2 amplification observed in the present study did not markedly differ from that in previous studies on advanced gastric cancer patients who received palliative chemotherapy [31,32]. However, current results are distinct from those of studies on resectable gastric cancer, which reported a relationship between FGFR2 amplification and poor prognosis [21-23].

Previous studies have reported that the FGFR2 protein was overexpressed by immunohistrochemistry (IHC) in $30-40 \%$ of gastric cancer patients undergoing curative resection $[33,34]$, although the incidence of FGFR2 gene amplification was only $4-10 \%$ in cases of resectable gastric cancer [21-23, 26, 35] and 4.4-11.5\% in cases of unresectable gastric cancer [31, 32]. Our frequency of FGFR2 amplification was consistent with that described in previous reports. The discordance in the reported incidences between protein expression and gene amplification could be explained by the heterogeneous amplification of FGFR2 in tissues or the varied antibodies and standard protocols used for IHC [29].

In present study, FGFR2 amplification was found to be associated with several clinicopathologic parameters, including younger age, poor ECOG performance status, extra-abdominal lymph node metastasis, bone metastasis, poorly differentiated histology, and Bormann type IV disease. These factors might reflect high tumor burden or aggressive biology, and have been suggested as poor prognostic factors in patients with advanced gastric cancer $[30,36]$. Consistent with current findings, previous studies have indicated an association between high-grade histology and FGFR2 amplification in resectable gastric cancer [22, 23, 37]. However, the relationship between age and FGFR2 amplification is controversial, as prior studies have reported both a significant association between FGFR2 amplification and older age [21] and no such relationship $[22,23]$. Furthermore, we found that FGFR2 amplification was related to a higher risk group by using our prognostic model that was developed by combining multiple clinicopathologic features of advanced gastric cancer [30]. These findings suggest that FGFR2 amplification is associated with negative prognostic factors in advanced gastric cancer, and could act as a confounding factor when we analyze its effect on survival.

Because some patients in the present study were diagnosed before 2012, we were unable to obtain information regarding HER2 expression or amplification in these cases. After conducting a cross-correlation analysis to assess the association between FGFR2 and HER 2 amplification, while allowing for the missing data, we found that these 2 factors were not related (data not shown). In fact, none of our patients presented with both FGFR2 and HER2 amplification, consistent with previous reports that have described the mutual exclusivity of these conditions [22, 32, 35, 37, 38].

$\mathrm{Su}$ et al. reported that FGFR2 amplification was more frequently observed in gastric cancer patients with a higher $\mathrm{N}$ stage and poorly differentiated histology [22]; these factors are considered to contribute to the 
development of recurrence and poor prognosis in FGFR2amplified resectable gastric cancer. Although it can be reasonably assumed that FGFR2 amplification is a negative prognostic indicator in patients with resectable gastric cancer [21-23], these results cannot be applied to metastatic or locally advanced unresectable gastric cancer, as noted in the present and recently published studies $[31,32]$. By using FISH testing, Shoji et al. showed that FGFR2-amplified gastric cancer patients in the palliative setting tended to have a shorter survival period. Even though the enrolled patients were treated with a heterogeneous treatment regimen, including trastuzumab or triplet regimens, the authors found a relationship between FGFR2 amplification and poor OS, which was significant on univariate analysis but was not significant on multivariate analysis [31]. More recently, Matsusaka et al. also reported no significant correlation between survival outcomes and FGFR2 amplification when using an arbitrarily determined cut-off value (copy number of 5) on qPCR [32]. Our current finding is consistent with those of previous studies, but we validated the reasonable cut-off value of a copy number of 8 on qPCR reported in our previous study to predict amplification via FISH [29]; hence, this study could suggest a more solid conclusion. In addition, our present study included the largest number of patients who received homogenous treatment, and could hence reliably indicate the survival outcome.

Although FGFR2 amplification is expected to be a new therapeutic target for advanced gastric cancer [25-28], a recent randomized phase II study comparing the efficacy of AZD4547 versus paclitaxel for advanced gastric cancer with FGFR2 amplification or polysomy did not show any significant benefits in the AZD4547 arm [39]. Notably, the authors observed marked intra-tumoral heterogeneity of FGFR2 amplification, which could potentially explain the failure of AZD4547 treatment. Hence, FGFR2 amplification is a questionable predictive marker for the response to FGFR2 inhibitor alone in metastatic or unresectable gastric cancer. Another possible hypothesis states that FGFR2 inhibitor monotherapy itself was not effective for advanced gastric cancer due to the presence of other escape mechanisms. Moreover, the FGFR2 inhibitor Ki23057 showed a synergistic effect with the chemotherapeutic agents in an in vitro test [40]. In addition, patients with FGFR2 protein expression determined by IHC, exhibited a better response (85.7\%) after combination treatment with pazopanib, capecitabine, and oxaliplatin in a phase II trial, in comparison with patients without FGFR2 protein expression (59.5\%) in advanced gastric cancer [41]. As the accompanying FGFR2 amplification did not affect the chemotherapy response in advanced gastric cancer in present and previous studies $[31,32]$, it could be hypothesized that the FGFR2 inhibitor would be more effective when combined with cytotoxic agents. Given the discordance between FGFR2 gene amplification and protein expression, this explanation is needed to validate by qPCR or FISH method in future trials.

Although FISH is considered the standard method for the diagnosis of gene amplification, the qPCR-based gene copy number assay has been found to be a reasonable alternative for detecting FGFR2 amplification [21, 29]. For qPCR of the FGFR2 gene in tissues with a tumor portion of $<70 \%$, microdissection will be needed. However, the qPCR-based method is less expensive and has comparable sensitivity, and can hence be adopted for broad practical use. We believe our current results were also reliable and applicable in practice.

In conclusion, FGFR2 amplification is not an independent prognostic predictor in patients with metastatic or locally advanced gastric cancer treated with palliative FP. Further validation is warranted to obtain a better clinical understanding of FGFR2 amplification in patients with gastric cancer treated with palliative chemotherapy.

\section{MATERIALS AND METHODS}

\section{Patient samples and clinical data}

Between June 2006 and December 2014, we screened 1367 patients who received palliative chemotherapy for metastatic or locally advanced unresectable gastric cancer and were registered in a single tertiary center gastric cancer registry. After a histological review, a total of 327 patients who had sufficient tissue specimens for qPCR and specimens comprised of $\geq 70 \%$ of tumor portion form pretreatment biopsied or surgically obtained FFPE tissues were selected for the analysis of the clinicopathologic features of FGFR2-amplified gastric cancer. Among these patients, 260 who were treated with first-line FP chemotherapy were analyzed for the prognostic impact of FGFR2 amplification. The medical records of all these patients were reviewed. This study adhered to the guidelines established by the declaration of Helsinki, and was approved by our institutional review board.

\section{Isolation of genomic DNA and real-time qPCR- based determination of the gene copy number of FGFR2}

Genomic DNA extraction, DNA concentration measurement, and real-time qPCR for determining the gene copy number of FGFR2 were conducted in a similar manner as in our previous study [29]. Genomic DNA was extracted from biopsy specimens or surgical FFPE tissues using a QIAamp DNA FFPE Tissue kit or QIAamp DNA Mini kit (Qiagen, Hilden, Germany). The DNA concentration was measured using the NanoDrop 2000 
spectrophotometer (Thermo Scientific, Waltham, MA). To determine the gene copy number of FGFR2, pre-designed TaqMan Copy Number Assays were used (Applied Biosystems). For real-time PCR, we prepared a total volume of $10 \mu \mathrm{L}$ of master mixture, which contained 10 ng of genomic DNA, $5 \mu \mathrm{L}$ of TaqMan genotyping master mix, and each primer. The primer IDs were HS05182482 cn (intron 14 and 15) and Hs05114211_cn (intron 12). The telomerase reverse transcriptase (TERT) gene and human genomic DNA (Takara) were used as internal references for the copy number and normal control, respectively. The thermal cycling conditions were as follows: $10 \mathrm{~min}$ at $95^{\circ} \mathrm{C}$, followed by 40 cycles of $15 \mathrm{~s}$ at $95^{\circ} \mathrm{C}$ and 60 $\mathrm{S}$ at $60^{\circ} \mathrm{C}$. The results were analyzed using the ABI PRISM 7900HT Sequence Detection System (Applied Biosystems).

\section{Statistical analysis}

To analyze the relationship between FGFR2 amplification and the clinical features and survival outcomes of gastric cancer, the patients were classified as having FGFR2 amplification based on the presence of an FGFR2 qPCR gene copy number of $\geq 8$, according to our previous study [29]. PFS was defined as the duration between the start of FP chemotherapy and tumor progression or death by any cause. Moreover, OS was estimated from the date of the initial first-line FP session until death by any cause. Data were censored if the patients were free of progression or alive at the final follow-up. Categorical variables were evaluated using the chi-square test or Fisher's exact test, as appropriate. The KaplanMeier method was used to estimate PFS and OS. Survival curves were compared using the log-rank test according to FGFR2 amplification. By multivariate analysis, the Cox proportional hazard model was used, and we included potent prognostic factors: ECOG Performance Status $\geq$ 2, no gastrectomy, peritoneal metastasis, bone metastasis, lung metastasis, ALP $>120 \mathrm{IU} / \mathrm{L}$, albumin $<3.3 \mathrm{~g} / \mathrm{dL}$, and total bilirubin $>1.2 \mathrm{mg} / \mathrm{dL}[30]$.

All statistical analyses were performed using the Statistical Package for the Social Sciences version 21 (IBM Co., Armonk, NY). All tests were two-sided with $5 \%$ defined as the level of significance.

\section{ACKNOWLEDGMENTS AND FUNDING}

This research was supported by a grant from the Korea Health Technology R\&D Project through the Korea Health Industry Development Institute (KHIDI), funded by the Ministry of Health \& Welfare, Republic of Korea (grant number: HI12C1785).

\section{CONFLICTS OF INTEREST}

Y-K Kang received a research grant from Bayer, Daehwa, Novartis, Ono, Roche, and Taiho. The other authors declare no conflict of interest.

\section{REFERENCES}

1. Wohrer SS, Raderer M, Hejna M. Palliative chemotherapy for advanced gastric cancer. Ann Oncol. 2004; 15:15851595.

2. Torre LA, Bray F, Siegel RL, Ferlay J, Lortet-Tieulent J, Jemal A. Global cancer statistics, 2012. CA Cancer J Clin. 2015; 65:87-108.

3. Jung KW, Won YJ, Oh CM, Kong HJ, Cho H, Lee JK, Lee DH, Lee KH. Prediction of Cancer Incidence and Mortality in Korea, 2016. Cancer Res Treat. 2016; 48:451-457.

4. Catalano V, Labianca R, Beretta GD, Gatta G, de Braud F, Van Cutsem E. Gastric cancer. Crit Rev Oncol Hematol. 2009; 71:127-164.

5. Van Cutsem E, Moiseyenko VM, Tjulandin S, Majlis A, Constenla M, Boni C, Rodrigues A, Fodor M, Chao Y, Voznyi E, Risse ML, Ajani JA. Phase III study of docetaxel and cisplatin plus fluorouracil compared with cisplatin and fluorouracil as first-line therapy for advanced gastric cancer: a report of the V325 Study Group. J Clin Oncol. 2006; 24:4991-4997.

6. Cunningham D, Starling N, Rao S, Iveson T, Nicolson M, Coxon F, Middleton G, Daniel F, Oates J, Norman AR. Capecitabine and oxaliplatin for advanced esophagogastric cancer. N Engl J Med. 2008; 358:36-46.

7. Kang YK, Kang WK, Shin DB, Chen J, Xiong J, Wang J, Lichinitser M, Guan Z, Khasanov R, Zheng L, Philco-Salas M, Suarez T, Santamaria J, et al. Capecitabine/cisplatin versus 5-fluorouracil/cisplatin as first-line therapy in patients with advanced gastric cancer: a randomised phase III noninferiority trial. Ann Oncol. 2009; 20:666-673.

8. Ajani JA, Rodriguez W, Bodoky G, Moiseyenko V, Lichinitser M, Gorbunova V, Vynnychenko I, Garin A, Lang I, Falcon S. Multicenter phase III comparison of cisplatin/S-1 with cisplatin/infusional fluorouracil in advanced gastric or gastroesophageal adenocarcinoma study: the FLAGS trial. J Clin Oncol. 2010; 28:1547-1553.

9. Kang YK, Yoon DH, Ryoo BY, Ryu MH. Recent advances in chemotherapy for advanced gastric cancer. Asia Pac J Oncol Hematol. 2010; 2:67-74.

10. Bang YJ, Van Cutsem E, Feyereislova A, Chung HC, Shen L, Sawaki A, Lordick F, Ohtsu A, Omuro Y, Satoh T, Aprile G, Kulikov E, Hill J, et al. Trastuzumab in combination with chemotherapy versus chemotherapy alone for treatment of HER2-positive advanced gastric or gastro-oesophageal junction cancer (ToGA): a phase 3, open-label, randomised controlled trial. Lancet. 2010; 376:687-697. 
11. Wilke H, Muro K, Van Cutsem E, Oh SC, Bodoky G, Shimada Y, Hironaka S, Sugimoto N, Lipatov O, Kim TY, Cunningham D, Rougier P, Komatsu Y, et al. Ramucirumab plus paclitaxel versus placebo plus paclitaxel in patients with previously treated advanced gastric or gastrooesophageal junction adenocarcinoma (RAINBOW): a double-blind, randomised phase 3 trial. Lancet Oncol. 2014; 15:1224-1235.

12. Ohtsu A, Shah MA, Van Cutsem E, Rha SY, Sawaki A, Park SR, Lim HY, Yamada Y, Wu J, Langer B, Starnawski M, Kang YK. Bevacizumab in combination with chemotherapy as first-line therapy in advanced gastric cancer: a randomized, double-blind, placebo-controlled phase III study. J Clin Oncol. 2011; 29:3968-3976.

13. Ohtsu A, Ajani JA, Bai YX, Bang YJ, Chung HC, Pan HM, Sahmoud T, Shen L, Yeh KH, Chin K, Muro K, Kim YH, Ferry D, et al. Everolimus for previously treated advanced gastric cancer: results of the randomized, double-blind, phase III GRANITE-1 study. J Clin Oncol. 2013; 31:39353943.

14. Lordick F, Kang YK, Chung HC, Salman P, Oh SC, Bodoky G, Kurteva G, Volovat C, Moiseyenko VM, Gorbunova V, Park JO, Sawaki A, Celik I, et al. Capecitabine and cisplatin with or without cetuximab for patients with previously untreated advanced gastric cancer (EXPAND): a randomised, open-label phase 3 trial. Lancet Oncol. 2013; 14:490-499.

15. Eswarakumar VP, Lax I, Schlessinger J. Cellular signaling by fibroblast growth factor receptors. Cytokine Growth Factor Rev. 2005; 16:139-149.

16. Dailey L, Ambrosetti D, Mansukhani A, Basilico C. Mechanisms underlying differential responses to FGF signaling. Cytokine Growth Factor Rev. 2005; 16:233-247.

17. Turner N, Lambros MB, Horlings HM, Pearson A, Sharpe R, Natrajan R, Geyer FC, van Kouwenhove M, Kreike B, Mackay A, Ashworth A, van de Vijver MJ, Reis-Filho JS. Integrative molecular profiling of triple negative breast cancers identifies amplicon drivers and potential therapeutic targets. Oncogene. 2010; 29:2013-2023.

18. Heiskanen M, Kononen J, Barlund M, Torhorst J, Sauter G, Kallioniemi A, Kallioniemi O. CGH, cDNA and tissue microarray analyses implicate FGFR2 amplification in a small subset of breast tumors. Anal Cell Pathol. 2001; 22:229-234.

19. Jang JH, Shin KH, Park JG. Mutations in fibroblast growth factor receptor 2 and fibroblast growth factor receptor 3 genes associated with human gastric and colorectal cancers. Cancer Res. 2001; 61:3541-3543.

20. Mor O, Ranzani GN, Ravia Y, Rotman G, Gutman M, Manor A, Amadori D, Houldsworth J, Hollstein M, Schwab M, Shiloh Y. DNA amplification in human gastric carcinomas. Cancer Genet Cytogenet. 1993; 65:111-114.

21. Matsumoto K, Arao T, Hamaguchi T, Shimada Y, Kato K, Oda I, Taniguchi H, Koizumi F, Yanagihara K, Sasaki H, Nishio K, Yamada Y. FGFR2 gene amplification and clinicopathological features in gastric cancer. Br J Cancer. 2012; 106:727-732.

22. Su X, Zhan P, Gavine PR, Morgan S, Womack C, Ni X, Shen D, Bang YJ, Im SA, Ho Kim W, Jung EJ, Grabsch HI, Kilgour E. FGFR2 amplification has prognostic significance in gastric cancer: results from a large international multicentre study. Br J Cancer. 2014; 110:967-975.

23. Jung EJ, Jung EJ, Min SY, Kim MA, Kim WH. Fibroblast growth factor receptor 2 gene amplification status and its clinicopathologic significance in gastric carcinoma. Hum Pathol. 2012; 43:1559-1566.

24. Andre F, Bachelot T, Campone M, Dalenc F, Perez-Garcia JM, Hurvitz SA, Turner N, Rugo H, Smith JW, Deudon S, Shi M, Zhang Y, Kay A, et al. Targeting FGFR with dovitinib (TKI258): preclinical and clinical data in breast cancer. Clin Cancer Res. 2013; 19:3693-3702.

25. Guagnano V, Kauffmann A, Wohrle S, Stamm C, Ito M, Barys L, Pornon A, Yao Y, Li F, Zhang Y, Chen Z, Wilson CJ, Bordas V, et al. FGFR genetic alterations predict for sensitivity to NVP-BGJ398, a selective pan-FGFR inhibitor. Cancer Discov. 2012; 2:1118-1133.

26. Xie L, Su X, Zhang L, Yin X, Tang L, Zhang X, Xu Y, Gao Z, Liu K, Zhou M, Gao B, Shen D, Zhang L, et al. FGFR2 gene amplification in gastric cancer predicts sensitivity to the selective FGFR inhibitor AZD4547. Clin Cancer Res. $2013 ; 19: 2572-2583$.

27. Nakamura K, Yashiro M, Matsuoka T, Tendo M, Shimizu T, Miwa A, Hirakawa K. A novel molecular targeting compound as K-samII/FGF-R2 phosphorylation inhibitor, Ki23057, for Scirrhous gastric cancer. Gastroenterology. 2006; 131:1530-1541.

28. Bai A, Meetze K, Vo NY, Kollipara S, Mazsa EK, Winston WM, Weiler S, Poling LL, Chen T, Ismail NS, Jiang J, Lerner L, Gyuris J, et al. GP369, an FGFR2-IIIb-specific antibody, exhibits potent antitumor activity against human cancers driven by activated FGFR2 signaling. Cancer Res. 2010; 70:7630-7639.

29. Park YS, Na YS, Ryu MH, Lee CW, Park HJ, Lee JK, Park SR, Ryoo BY, Kang YK. FGFR2 Assessment in Gastric Cancer Using Quantitative Real-Time Polymerase Chain Reaction, Fluorescent In Situ Hybridization, and Immunohistochemistry. Am J Clin Pathol. 2015; 143:865872.

30. Koo DH, Ryoo BY, Kim HJ, Ryu MH, Lee SS, Moon JH, Chang HM, Lee JL, Kim TW, Kang YK. A prognostic model in patients who receive chemotherapy for metastatic or recurrent gastric cancer: validation and comparison with previous models. Cancer Chemother Pharmacol. 2011; 68:913-921.

31. Shoji H, Yamada Y, Okita N, Takashima A, Honma Y, Iwasa S, Kato K, Hamaguchi T, Shimada Y. Amplification of FGFR2 Gene in Patients with Advanced Gastric Cancer Receiving Chemotherapy: Prevalence and Prognostic Significance. Anticancer Res. 2015; 35:5055-5061. 
32. Matsusaka S, Kobunai T, Yamamoto N, Chin K, Ogura M, Tanaka G, Matsuoka K, Ishikawa Y, Mizunuma N, Yamaguchi T. Prognostic impact of KRAS mutant type and MET amplification in metastatic and recurrent gastric cancer patients treated with first-line S-1 plus cisplatin chemotherapy. Genes Cancer. 2016; 7:27-35.

33. Hattori $\mathrm{Y}$, Itoh $\mathrm{H}$, Uchino $\mathrm{S}$, Hosokawa $\mathrm{K}$, Ochiai A, Ino Y, Ishii H, Sakamoto H, Yamaguchi N, Yanagihara K, Hirohashi S, Sugimura T, Terada M. Immunohistochemical detection of K-sam protein in stomach cancer. Clin Cancer Res. 1996; 2:1373-1381.

34. Toyokawa T, Yashiro M, Hirakawa K. Co-expression of keratinocyte growth factor and $\mathrm{K}$-sam is an independent prognostic factor in gastric carcinoma. Oncol Rep. 2009; 21:875-880.

35. Deng N, Goh LK, Wang H, Das K, Tao J, Tan IB, Zhang S, Lee M, Wu J, Lim KH, Lei Z, Goh G, Lim QY, et al. A comprehensive survey of genomic alterations in gastric cancer reveals systematic patterns of molecular exclusivity and co-occurrence among distinct therapeutic targets. Gut. 2012; 61:673-684.

36. Kim JG, Ryoo BY, Park YH, Kim BS, Kim TY, Im YH, Kang YK. Prognostic factors for survival of patients with advanced gastric cancer treated with cisplatin-based chemotherapy. Cancer Chemother Pharmacol. 2008; 61:301-307.
37. Das K, Gunasegaran B, Tan IB, Deng N, Lim KH, Tan P. Mutually exclusive FGFR2, HER2, and KRAS gene amplifications in gastric cancer revealed by multicolour FISH. Cancer Lett. 2014; 353:167-175.

38. Liu YJ, Shen D, Yin X, Gavine P, Zhang T, Su X, Zhan P, Xu Y, Lv J, Qian J, Liu C, Sun Y, Qian Z, et al. HER2, MET and FGFR2 oncogenic driver alterations define distinct molecular segments for targeted therapies in gastric carcinoma. Br J Cancer. 2014; 110:1169-1178.

39. Bang YJ, Van Cutsem E, Mansoor W, Petty RD, Chao Y, Cunningham D, Ferry D, Landers D, Stockman P, Smith NR, Geh C, Kilgour E. A randomized, open-label phase II study of AZD4547 (AZD) versus Paclitaxel (P) in previously treated patients with advanced gastric cancer (AGC) with Fibroblast Growth Factor Receptor 2 (FGFR2) polysomy or gene amplification (amp): SHINE study. J Clin Oncol 33, 2015 (suppl; abstr 4014), pp. 4014.

40. Qiu H, Yashiro M, Zhang X, Miwa A, Hirakawa K. A FGFR2 inhibitor, Ki23057, enhances the chemosensitivity of drug-resistant gastric cancer cells. Cancer Lett. 2011; 307:47-52.

41. Kim ST, Ahn S, Lee J, Lee SJ, Park SH, Park YS, Lim HY, Kang WK, Kim KM, Park JO. Value of FGFR2 expression for advanced gastric cancer patients receiving pazopanib plus CapeOX (capecitabine and oxaliplatin). J Cancer Res Clin Oncol. 2016; 142:1231-1237. 